\title{
Differentiation of Cultured Keratinocytes Promotes the Adherence of Streptococcus pyogenes
}

\author{
Gary L. Darmstadt, ${ }^{\star}$ Philip Fleckman, ${ }^{\ddagger}$ Mechthild Jonas, ${ }^{\S}$ Emil Chi, ${ }^{\S}$ and Craig E. Rubens ${ }^{\star}$ \\ $*$ Division of Infectious Disease, Department of Pediatrics CH-32, Children's Hospital \& Medical Center; ${ }^{*}$ Department of Medicine \\ (Dermatology); and ${ }^{\S}$ Department of Pathology, University of Washington School of Medicine, Seattle, Washington 98105
}

\begin{abstract}
Based on a consideration of the histopathology of nonbullous impetigo that shows localization of Streptococcus pyogenes to highly differentiated, subcorneal keratinocytes, we hypothesized that adherence of an impetigo strain of $S$. pyogenes would be promoted by terminal differentiation of keratinocytes. An assay was developed in which $S$. pyogenes adhered via pilus-like projections from the cell wall to the surface of cultured human keratinocytes in a time- and inoculum-dependent manner suggestive of a receptor-mediated process.
\end{abstract}

Terminal differentiation of keratinocytes was induced by increasing the calcium concentration in the growth medium, and was confirmed by morphologic analysis using electron microscopy. Adherence of $S$. pyogenes was three and fourfold greater to keratinocytes differentiated in $\mathbf{1 . 0}$ and $1.5 \mathrm{mM}$ calcium, respectively, compared with undifferentiated keratinocytes in $0.15 \mathrm{mM}$ calcium. The presence of calcium during the adherence assay further enhanced adherence nearly twofold. Adherence occurred preferentially to sites of contact between adjacent keratinocytes, suggesting that the keratinocyte receptor may be a molecule involved in cell-to-cell adhesion. In contrast, nonpathogenic Streptococcus gordonii adhered poorly to keratinocytes regardless of their state of terminal differentiation, and adherence of a pharyngeal strain of $S$. pyogenes was twofold greater to undifferentiated than differentiated keratinocytes.

This is the first report of in vitro adherence of $S$. pyogenes to keratinocytes in a manner that emulates human impetigo. Adherence of only the impetigo strain, and not the pharyngeal strain of $S$. pyogenes or the nonpathogenic $S$. gorgonii isolate, was promoted by keratinocyte differentiation. This result provides a model system for investigating the molecular pathogenesis of streptococcal skin infections. (J. Clin. Invest. 1998. 101:128-136.) Key words: calcium • pathogenesis $\bullet$ skin infection $\bullet$ impetigo $\bullet$ model

Address correspondence to Craig E. Rubens, M.D., Ph.D., Professor, Division of Infectious Disease, Department of Pediatrics CH-32, Children's Hospital \& Medical Center, 4800 Sand Point Way NE, Seattle, WA 98105. Phone: 206-526-2073; FAX: 206-527-3890; E-mail: cruben@chmc.org

Received for publication 20 May 1997 and accepted in revised form 29 October 1997.

J. Clin. Invest.

(C) The American Society for Clinical Investigation, Inc. 0021-9738/98/01/0128/09 \$2.00

Volume 101, Number 1, January 1998, 128-136

http://www.jci.org

\section{Introduction}

Group A streptococci are unsurpassed among bacterial pathogens in their ability to cause a wide variety of cutaneous infections, ranging from superficial impetigo to fulminant invasive necrotizing fasciitis $(1,2)$. Streptococcus pyogenes is isolated from $\sim 30 \%$ of all skin infections in children (3). The global incidence of severe, invasive disease due to $S$. pyogenes has increased dramatically in recent years, with the skin serving as the portal of entry in most cases (4-7). This fact has provided impetus for developing a greater understanding of the molecular pathogenesis of streptococcal skin infections.

Impetigo is the most common bacterial skin infection, accounting for $\sim 10 \%$ of all pediatric skin problems, and $1-2 \%$ of all pediatric visits (8-11). Histopathologically, an acute inflammatory infiltrate is seen within a vesicle located between the granular and corneal layers. Initial localization of nonbullous impetigo to the subcorneal epidermis suggests that $S$. pyogenes binding and the initiation of host defense mechanisms, including generation of the chemokine gradient that attracts the inflammatory infiltrate, occur at this location where keratinocytes are most highly differentiated $(12,13)$. We selected impetigo as our model for streptococcal skin infections, as correlates of its well-defined histopathology can be modeled and manipulated in vitro.

Pathogenesis of skin infection involves a dynamic interaction between host and pathogen in a manner that allows for local replication of bacteria. The initial step in the pathogenesis of group A streptococcal skin infection may involve adherence of the bacteria via its adhesin(s) to a host cell receptor(s), although this is yet unproven. The type of adhesin used for specific binding appears to vary depending on the streptococcal strain and type of host cell and tissue involved (14). Our knowledge of the mechanism of adherence of $S$. pyogenes is based to date almost exclusively on studies with respiratory epithelium. These findings, however, may not be applicable to the skin. Epidermal and mucosal keratinocytes exist in markedly different environments, the former having a dry surface, while the latter is bathed continually in a complex solution (i.e., saliva or mucous). Furthermore, the array of molecules expressed by epidermal and mucosal epithelial cells, including those on their surface, differ. For example, fibronectin, which is the primary receptor for adherence of $S$. pyogenes to respiratory epithelium (15), is not expressed by keratinocytes except in wounded or inflamed epidermis (16). Oropharyngeal mucosal epithelial cells, on the other hand, lack both a corneal layer, which appears to provide sufficient protection to prevent skin infection from developing (17), and a granular layer to which infection is localized in impetigo. Furthermore, strains of $S$. pyogenes can be segregated into those that have a propensity to cause pyogenic skin and soft-tissue infections, and those that cause tonsillopharyngitis. Only a minority of strains cause infections in both sites $(18,19)$. 
The present studies examine adherence of $S$. pyogenes to cultured human keratinocytes in various stages of terminal differentiation. Based on a consideration of the histopathology of impetigo, we hypothesized that adherence of an impetigo strain of $S$. pyogenes would be promoted by keratinocyte differentiation.

\section{Methods}

Bacterial strains. S. pyogenes strain 3732, provided by Dr. Susan K. Hollingshead (University of Alabama-Birmingham), is an M-protein 52 serotype isolated from a lesion of impetigo. It is a class II strain with emm gene pattern D (19), characteristic of impetigo strains. $S$. pyogenes strain $87-263$ is an M1 serotype isolated from the throat of a patient with uncomplicated pharyngitis (20). Streptococcus gordonii (Challis strain), which does not cause skin infections, was used as a negative control.

Radiolabeling of bacteria. Bacteria were stored at $-70^{\circ} \mathrm{C}$ in suspensions of $20 \%$ glycerol (J.T. Baker, Inc., Phillipsburg, NJ) in ToddHewett broth (THB) ${ }^{1}$ (Difco Laboratories Inc., Detroit, MI). Inocula from frozen cultures were placed in $10 \mathrm{cc}$ THB and grown overnight at $37^{\circ} \mathrm{C}$. Aliquots $(0.5 \mathrm{cc})$ of the overnight stationary-phase suspensions of bacteria in THB were inoculated into $9.5 \mathrm{cc}$ fresh THB and incubated at $37^{\circ} \mathrm{C}$ for $2 \mathrm{~h}$ until log-phase growth was achieved (OD at $600 \mathrm{~nm}=0.5$ to 0.6$)$. Growth curves for each strain of bacteria showed that log-phase growth was reached under these conditions within $\sim 90-120$ min (data not shown). Bacteria were washed twice by centrifugation in a Z230M Microfuge (Hermle Scientific, Gosheim, Germany) and resuspended in 1 cc RPMI 1640 (Mediatech Inc., Herdon, VA) without L-leucine. Radiolabeled L- $\left[{ }^{3} \mathrm{H}\right]$ leucine (50 $\mu \mathrm{Ci}, 131 \mathrm{Ci} / \mathrm{mmol}, 1 \mathrm{mCi} / \mathrm{cc}$; Amersham Corp., Arlington Heights, IL) was added, and the bacteria were incubated at $37^{\circ} \mathrm{C}$ for $1 \mathrm{~h}$. THB $(9 \mathrm{cc})$ was added, and the suspensions were incubated for $1 \mathrm{~h}$ at $37^{\circ} \mathrm{C}$ to bring the bacteria to log-phase growth. After pelleting the bacteria, they were suspended in $10 \mathrm{cc}$ THB with $20 \%$ glycerol and frozen at $-70^{\circ} \mathrm{C}$ in 1 -cc aliquots. Bacterial viability and adherence were unaffected by freezing.

Frozen L- $\left[{ }^{3} \mathrm{H}\right]$ leucine-labeled bacteria were thawed, and $0.5 \mathrm{cc}$ THB was added to $1 \mathrm{cc}$ of the bacterial suspensions in a microfuge tube. The bacteria were pelleted, resuspended in $1 \mathrm{cc}$ THB, and washed once. Washed bacteria were resuspended in $1 \mathrm{cc}$ THB and incubated at $37^{\circ} \mathrm{C}$ for $15 \mathrm{~min}$. Bacteria were pelleted and resuspended in $10 \mathrm{cc}$ cold HBSS with $5 \%$ BSA (endotoxin $<0.1 \mathrm{ng} / \mathrm{ml}$, cell culture-tested; Sigma Chemical Co., St. Louis, MO) or $0.25 \%$ gelatin (Difco Laboratories, Inc.) to block nonspecific adherence to the tissue culture plate. Bacterial suspensions were incubated at $4^{\circ} \mathrm{C}$ for 30 $\min$ before initiation of adherence assays. $50-\mu \mathrm{l}$ aliquots of the suspensions were counted for radioactivity (cpm; three replications). Suspensions were diluted to $10^{-4}$, and $20-\mu l$ aliquots were plated on Todd-Hewett agar (THA) for determination of CFU/cc (three replications). Ratio of CFU-to-cpm was determined for each preparation, and ranged from 200 to 300 .

Keratinocyte culture. Keratinocytes were isolated enzymatically from neonatal foreskins in complete keratinocyte growth media (cKGM, keratinocyte basal media supplemented with $0.1 \mathrm{ng} / \mathrm{ml}$ human recombinant epidermal growth factor, $5 \mu \mathrm{g} / \mathrm{ml}$ insulin, $0.5 \mu \mathrm{g} / \mathrm{ml}$ hydrocortisone, $50 \mu \mathrm{g} / \mathrm{ml}$ gentamicin, $50 \mathrm{ng} / \mathrm{ml}$ amphotericin B, and $0.15 \mathrm{mM}$ calcium; Clonetics, San Diego, CA) as described previously (21). The $10^{6}$ cells were seeded in $5 \mathrm{cc}$ cKGM with $30 \mu \mathrm{g} / \mathrm{ml}$ bovine pituitary extract (BPE) into a $25-\mathrm{cm}^{2}$ flask (Becton-Dickinson, Inc., Rutherford, $\mathrm{NJ}$ ) in a humidified atmosphere containing $5 \% \mathrm{CO}_{2}$ at

1. Abbreviations used in this paper: BPE, bovine pituitary extract; cKGM, complete keratinocyte growth media; THA, Todd-Hewett agar; THB, Todd-Hewett broth. $36.7^{\circ} \mathrm{C}$. Cells were washed with HBSS the next day, and fed fresh cKGM without BPE every 2-3 d. After $\sim 5-7 \mathrm{~d}$, the primary keratinocytes at $\sim 80 \%$ of confluence were trypsinized and frozen in freezing solution ( $80 \%$ cKGM, $10 \%$ FCS, $10 \%$ DMSO; Sigma Chemical Co.) at a concentration of $\sim 10^{6}$ keratinocytes/cc.

For use in experiments, keratinocytes were thawed at room temperature and seeded in $\mathrm{cKGM}$ with BPE into a $25-\mathrm{cm}^{2}$ flask. Fresh cKGM without BPE was provided the next day and every 2-3 d thereafter. At $80 \%$ of confluence, cells were passaged into 6-well tissue culture plates (Corning Glass Works, Corning, NY) for adherence experiments. 60,000 keratinocytes were seeded in cKGM with BPE into each well. Growth medium was changed the next day to cKGM without BPE. At confluence, keratinocyte monolayers grown in $0.15 \mathrm{mM}$ calcium in 6-well tissue culture plates contained $\sim 2 \times 10^{6}$ keratinocytes per well.

Keratinocyte differentiation. Differentiation of cultured keratinocytes can be regulated by adjusting the extracellular calcium concentration (22-29). When keratinocytes in 6-well tissue culture plate wells reached $80 \%$ of confluence, the extracellular calcium concentration was maintained at $0.15 \mathrm{mM}$, or increased to $0.6-1.5 \mathrm{mM}$ to induce keratinocyte differentiation. Keratinocytes were grown for an additional $7 \mathrm{~d}$ in the adjusted calcium concentration before adherence or morphologic assays. Differentiation was assessed morphologically by electron microscopy.

Calcium determination. Calcium concentration in keratinocyte growth and incubation media was confirmed using an ion-selective electrode on an AVL 988-4 Electrolyte Analyzer (AVL Scientific Corp., Rosewell, GA), as described previously (30). The range of detection of ionized calcium was $0.12-6.0 \mathrm{mM}$, with resolution to 0.001 $\mathrm{mM}$. Neither $0.25 \%$ gelatin or $5 \%$ BSA used for blocking nonspecific adherence, or BPE used during plating of keratinocytes, contributed measurable concentrations of calcium to the media (data not shown).

Transmission electron microscopy. Keratinocytes were fixed with $2.5 \%$ glutaraldehyde in $0.1 \mathrm{M}$ sodium cacodylate buffer (Ted Pella Inc., Redding, CA) for $2 \mathrm{~h}$ at room temperature, washed with $0.1 \mathrm{M}$ cacodylate buffer ( $\mathrm{pH} 7.4$ ), and postfixed in $1 \% \mathrm{OsO}_{4}$ (Ted Pella Inc.) in double-distilled $\mathrm{H}_{2} \mathrm{O}$ as described previously (31). Samples were dehydrated using a graded alcohol series, cells were embedded in Medcast (Ted Pella Inc.), thin sections were cut at a ultramicrotome with a diamond knife (LKB-Produkter AB, Bromma, Sweden), stained with uranyl acetate (Ted Pella Inc.) and lead citrate (Ted Pella Inc.), and examined with a JEOL-1200EX transmission electron microscope (JEOL Ltd., Tokyo, Japan) at $80 \mathrm{kV}$.

Bacterial adherence assay. Wells without keratinocytes served as a negative control. Each well with or without cultured keratinocytes was washed three times with $1 \mathrm{cc}$ cold HBSS. Before inoculating cultures with bacteria, nonspecific sites for adherence on keratinocytes were blocked by exposure to $0.25 \%$ gelatin or $5 \%$ BSA in HBSS for $2 \mathrm{~h}$ at $4^{\circ} \mathrm{C}$. After blocking, the HBSS/BSA solution was removed by aspirating to dryness, and $1.5 \mathrm{cc}$ of a suspension of radiolabeled bacteria containing $\sim 5 \times 10^{7}-1 \times 10^{8} \mathrm{CFU} / \mathrm{cc}$ HBSS with $0.25 \%$ gelatin or $5 \%$ BSA was added to each well. Multiplicity of infection ranged from $\sim 50-100$ bacteria per keratinocyte. Unless indicated otherwise, adherence occurred for $4 \mathrm{~h}$ at $4^{\circ} \mathrm{C}$ with no centrifugation of bacteria against the keratinocytes. Aliquots of the suspension were plated on THA to determine CFU/cc (three replications). To terminate adherence and remove nonspecifically adherent bacteria, each well was washed three times with $1 \mathrm{cc}$ HBSS at $4^{\circ} \mathrm{C}$. For each wash, the plate was vortexed for $10 \mathrm{~s}$ to dislodge nonspecifically adherent bacteria. Nonadherent bacteria were removed within three washes; additional washes did not alter the number of adherent bacteria (data not shown). $\mathrm{NaOH}(2 \mathrm{~N}, 1 \mathrm{cc})$ was added to each well, and the plate was incubated at $65^{\circ} \mathrm{C}$ for $1 \mathrm{~h}$. Judged by inspection under light microscopy, this procedure entirely lysed the keratinocytes. 50- $\mu$ l aliquots were removed for counting (three replications) on solid scintillant (Readycaps; Beckman Instruments Inc., Fullerton, CA). Counts per min in wells without keratinocytes (background) was subtracted from $\mathrm{cpm}$ in wells containing keratinocytes (bound) to correct for nonspe- 
cific adherence. Percent adherence was calculated as follows: (cpm bound - background $) /(\mathrm{cpm}$ added $-\mathrm{cpm}$ ambient $) \times 100$.

Bacterial internalization assay. To confirm that the bacterial adherence assay measured adherent, not internalized bacteria, the ability of $S$. pyogenes strain 3732 to enter cultured keratinocytes at $4^{\circ} \mathrm{C}$ was determined by a modification of methods described previously by Rubens et al. (32). In brief, a standard adherence assay as described above was performed at $4^{\circ} \mathrm{C}$ using an inoculum of $1 \times 10^{7}$ $\mathrm{CFU} / \mathrm{cc}{ }^{3} \mathrm{H}$-radiolabeled $\mathrm{S}$. pyogenes, followed by the addition of 5 $\mu \mathrm{g} / \mathrm{ml}$ penicillin and $100 \mu \mathrm{g} / \mathrm{ml}$ gentamicin in HBSS at $37^{\circ} \mathrm{C}$ for $4 \mathrm{~h}$ to kill extracellular bacteria remaining after adherence had been terminated by washing with HBSS. These antibiotics penetrate host cells to an insignificant degree (33), allowing for the survival of intracellular bacteria. After removing antibiotics from tissue culture plate wells with four washes of $4 \mathrm{cc}$ HBSS at room temperature, keratinocytes were dislodged from the tissue culture plates by incubation with $0.25 \%$ trypsin at $37^{\circ} \mathrm{C}$ for $5 \mathrm{~min}$. To release intracellular bacteria from keratinocytes, Triton X-100 (Sigma Chemical Co.) was added to a final concentration of $0.025 \%$. The number of viable intracellular bacteria was determined by plating an aliquot of the final suspension on THA. CFU recovered from wells without keratinocytes were subtracted from the CFU from wells containing keratinocytes. Total cellassociated bacteria was determined by scintillation counting of an aliquot of the final suspension. The percentage of the total inoculum added to each well that adhered to the surface of keratinocytes was determined by subtracting the number of intracellular bacteria from the cell-associated bacteria.

\section{Results}

Adherence to keratinocyte monolayers. An assay was developed that measured specific adherence of the $S$. pyogenes impetigo strain 3732 to cultured human foreskin keratinocytes.

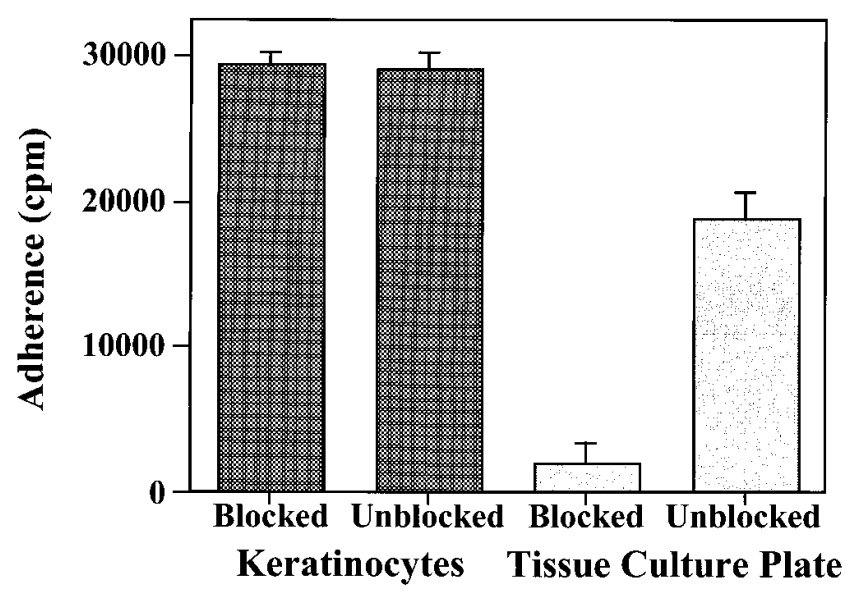

Figure 1. BSA blocked nonspecific adherence of Streptococcus pyogenes to the tissue culture plate, but did not affect adherence to keratinocytes. An M52 S. pyogenes impetigo strain (3732) was radiolabeled with L- $\left[{ }^{3} \mathrm{H}\right]$ leucine and suspended in HBSS. The bacteria and 6-well tissue culture plate wells with or without monolayers of confluent cultures of undifferentiated human foreskin keratinocytes grown in $0.15 \mathrm{mM}$ calcium were preincubated with $5 \%$ BSA in HBSS for $2 \mathrm{~h}$ at $4^{\circ} \mathrm{C}$. Adherence was then initiated by adding $2.1 \times 10^{8} \mathrm{CFU}$ of bacteria to each well, followed by centrifugation at 800 relative centrifugal force for $10 \mathrm{~min}$. Adherence occurred for $4 \mathrm{~h}$ at $4^{\circ} \mathrm{C}$, then nonadherent bacteria were removed by washing. Keratinocytes were solubilized with $\mathrm{NaOH}$, and radioactivity in an aliquot was determined by scintillation counting. Adherence to keratinocytes (hatched bars) and to the tissue culture plate (shaded bars) is expressed as the total cpm per well. Error bars represent \pm SD.

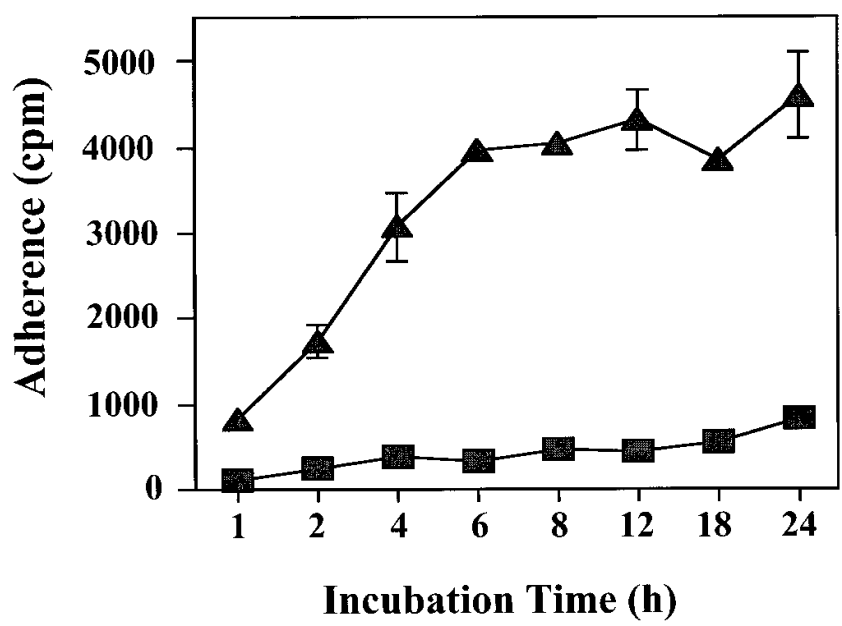

Figure 2. Adherence of Streptococcus pyogenes (strain 3732) to keratinocytes, not to the tissue culture plate, was saturated by $4-6 \mathrm{~h}$ incubation at $4^{\circ} \mathrm{C}$. Nonspecific sites for adherence on monolayers of undifferentiated keratinocytes grown in $0.15 \mathrm{mM}$ calcium and on bacteria were blocked by incubation with $5 \%$ BSA for $2 \mathrm{~h}$ at $4{ }^{\circ} \mathrm{C}$. Adherence to keratinocytes $(\triangle)$ or to the tissue culture plate $(\square)$ was initiated by adding $1.3 \times 10^{8} \mathrm{CFU}$ of radiolabeled $S$. pyogenes to confluent keratinocyte cultures at $4^{\circ} \mathrm{C}$. Centrifugation was not used to initiate adherence. Error bars represent \pm SD.

We preferred to use keratinocytes in early passage rather than an immortalized keratinocyte cell line to preserve expression of cell surface receptors for bacterial adherence that resemble those of keratinocytes in vivo.

We first sought to demonstrate that $S$. pyogenes adhered to monolayers of keratinocytes, and that nonspecific binding to exposed tissue culture well plastic could be blocked. Preincubation of keratinocytes and bacteria separately with 5\% BSA for $2 \mathrm{~h}$ before initiating adherence blocked nonspecific binding of bacteria to the tissue culture plate (Fig. 1). Blocking with BSA, however, had no effect on adherence of $S$. pyogenes to keratinocytes (Fig. 1). Similar adherence results were obtained when keratinocytes were preincubated with $0.25 \%$ gelatin as the blocking agent for 2 or $4 \mathrm{~h}$ (data not shown). Thus, either agent was suitable for blocking. Blockade of nonspecific adherence was effective at $4^{\circ} \mathrm{C}$, as adherence to the tissue culture plate was insignificant in comparison to adherence to keratinocytes during a 24 -h incubation (Fig. 2). At $37^{\circ} \mathrm{C}$, however, excessive nonspecific adherence to the tissue culture plate occurred despite preincubation with 5\% BSA (data not shown). Consequently, adherence assays were routinely performed at $4^{\circ} \mathrm{C}$ since adherence at $37^{\circ} \mathrm{C}$ was confounded by the high nonspecific background binding.

The adherence assay cannot distinguish between adherent or internalized bacteria, as it measures total cell-associated radiolabeled bacteria. The contribution of intracellular bacteria to total cell-associated bacteria was determined by measuring the number of bacteria that were internalized under the conditions of the adherence assay. After incubation at $4^{\circ} \mathrm{C}$ for $4 \mathrm{~h}$, $<0.01 \%$ of an inoculum of $8 \times 10^{7} \mathrm{CFU}$ was recovered in an internalization assay from keratinocytes cultured in either 0.15 $\mathrm{mM}$ or $1.0 \mathrm{mM}$ calcium (data not shown). This result indicates that the cpm measured in the adherence assays reflected bound, not intracellular bacteria. Lack of recovery of a signifi- 
cant number of intracellular bacteria was not due to bacterial death during their isolation in the internalization assay, as use of $0.25 \%$ trypsin or $0.025 \%$ Triton X-100 in the internalization assay did not affect viability of $S$. pyogenes (data not shown). Viability of keratinocytes also was unaffected during the assay as judged by their ability to exclude trypan blue stain, and by their maintenance of normal morphology under light and electron microscopy (data not shown).

Adherence that occurs via a receptor-mediated process should be saturable with increasing time of incubation and increasing bacterial inoculum. Adherence of $S$. pyogenes to monolayers of undifferentiated cultured human foreskin keratinocytes increased over time, becoming saturated at 4-6 h incubation with an inoculum of $9 \times 10^{7} \mathrm{CFU} / \mathrm{cc}\left(1.3 \times 10^{8} \mathrm{CFU} /\right.$ well; Fig. 2). The plateau in adherence was not due to loss of bacterial viability, as there was no difference in total CFU/cc recovered from the supernatant in wells after $0-24 \mathrm{~h}$ incubation (data not shown). Keratinocyte viability also was preserved over the 24-h incubation, as judged functionally by exclusion of trypan blue stain and morphologically by light and electron microscopy (data not shown).

At $4 \mathrm{~h}$ incubation, $\sim 1 \mathrm{CFU}$ of $S$. pyogenes bound per keratinocyte after inoculation with $10^{7} \mathrm{CFU} / \mathrm{cc}$; this figure rose 10 -fold to $\sim 10 \mathrm{CFU} /$ keratinocyte when the inoculum was increased to $10^{8} \mathrm{CFU} / \mathrm{cc}$ (Fig. 3). Total cell-associated CFU/keratinocyte increased at an accelerated rate as the inoculum was increased above $1 \times 10^{9} \mathrm{CFU} / \mathrm{cc}$. Under light microscopy, many of the cell-associated bacteria in wells inoculated with more than $1 \times 10^{9} \mathrm{CFU} / \mathrm{cc}$ appeared to be agglutinated to each other on the keratinocyte surface rather than bound directly to keratinocytes. Since the relationship between bound CFU/ke-

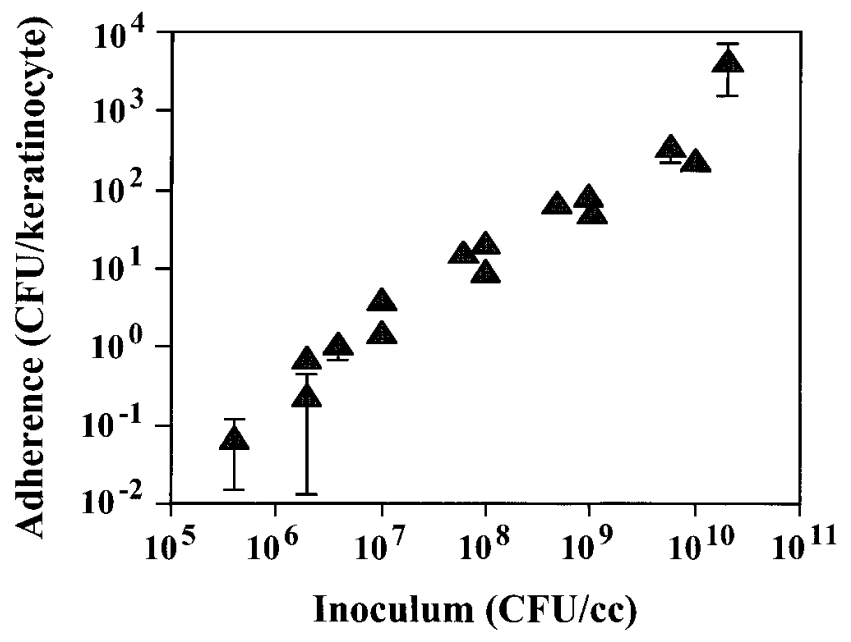

Figure 3. Adherence of Streptococcus pyogenes (strain 3732) to keratinocytes increased linearly as the bacterial inoculum was increased. $S$. pyogenes was added to confluent cultures of undifferentiated keratinocytes in $0.15 \mathrm{mM}$ calcium at $4^{\circ} \mathrm{C}$. Bacterial inoculum was varied as indicated. Adherence was terminated after $4 \mathrm{~h}$ by washing and vortexing off nonadherent bacteria. An aliquot of each bacterial inoculum was plated on Todd-Hewett agar for colony counting, and cpm of radioactivity was related to $\mathrm{CFU}$. Average number of keratinocytes per well was determined by dislodging keratinocytes with $0.25 \%$ trypsin and counting them with a hemocytometer. Data are expressed as CFU of $S$. pyogenes per keratinocyte as a function of the inoculum. Error bars represent \pm SD.

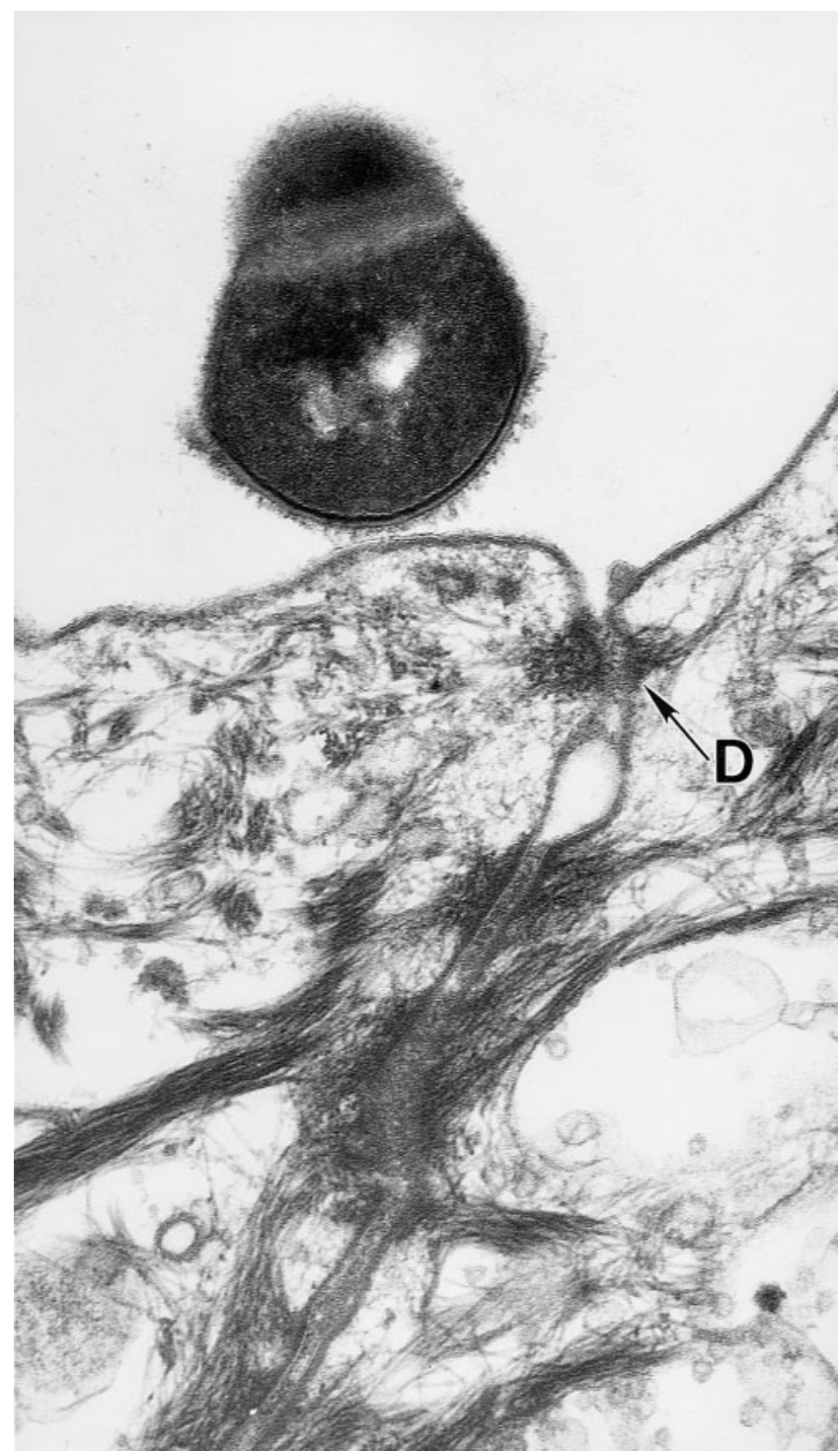

Figure 4. Streptococcus pyogenes (strain 3732) adhered by pilus-like cell wall projections to a cultured human foreskin keratinocyte adjacent to a site of contact ( $D$, desmosome) with another keratinocyte $(25,000 \times)$. Keratinocytes were grown to $80 \%$ of confluence in keratinocyte growth media containing $0.15 \mathrm{mM}$ extracellular calcium, then induced to differentiate in $1.0 \mathrm{mM}$ calcium for an additional $7 \mathrm{~d}$ before adding $S$. pyogenes. Electron microscopy was performed after incubation of bacteria with keratinocytes for $24 \mathrm{~h}$ at $4^{\circ} \mathrm{C}$.

ratinocyte and inoculum was linear with inocula ranging from $10^{6}$ to $10^{8} \mathrm{CFU} / \mathrm{cc}$ (Fig. 3), adherence assays were routinely performed using inocula of $1 \times 10^{7}-1 \times 10^{8} \mathrm{CFU} / \mathrm{cc}$.

Together, these data demonstrate time-dependent saturable adherence of $S$. pyogenes to undifferentiated human keratinocytes, suggestive of a receptor-mediated process. By electron microscopy, bacteria were found to adhere to keratinocytes by pilus-like cell-wall projections (Fig. 4), suggesting that the bacterial adhesin for attachment resides on these structures.

Adherence to differentiated keratinocytes. Based on a consideration of the histopathology of impetigo, in which bacteria 


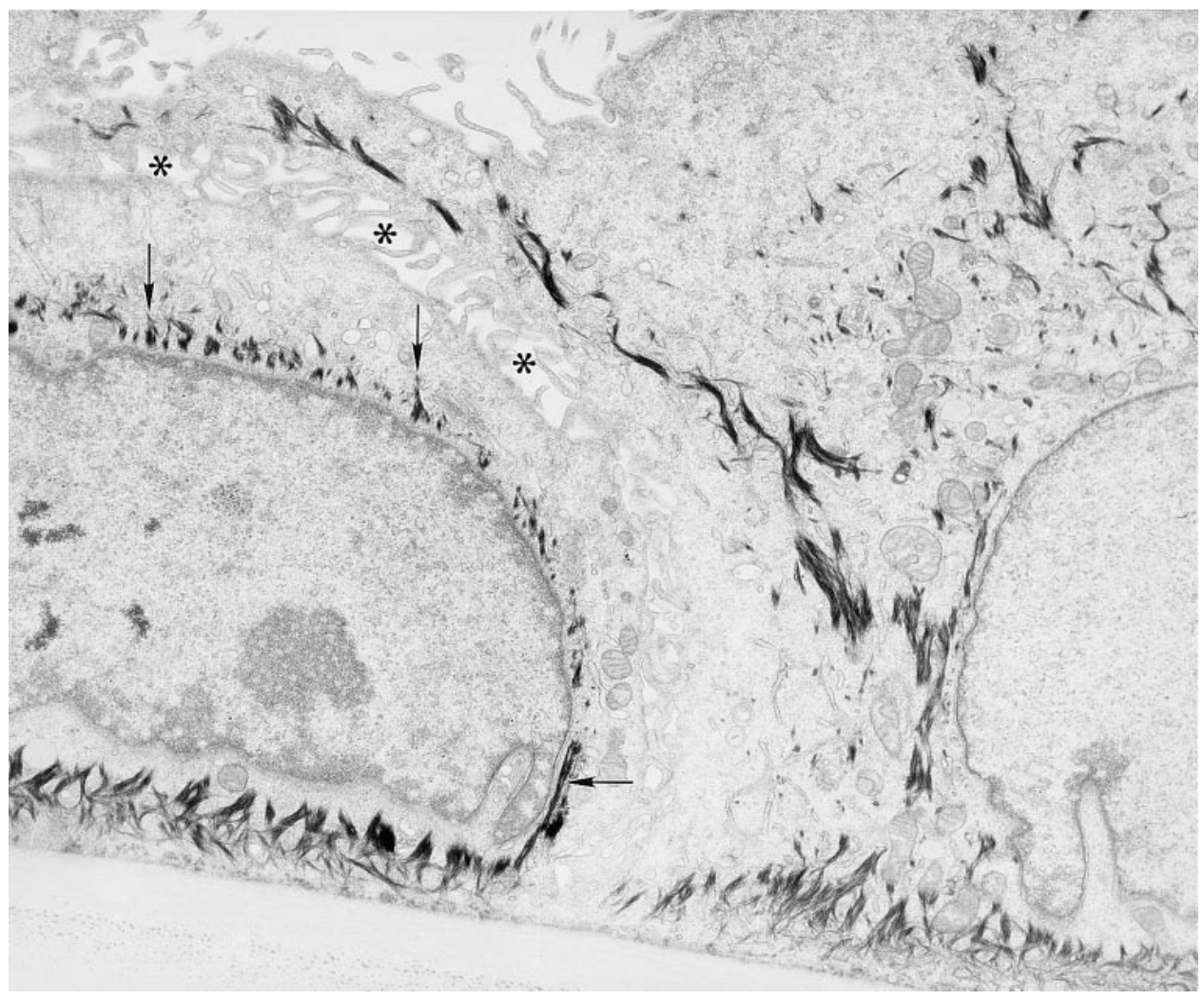

Figure 5. Electron micrograph of undifferentiated keratinocytes grown to confluence in media containing $0.15 \mathrm{mM}$ calcium. Keratinocytes grew in a monolayer and had a perinuclear distribution of keratin intermediate filaments (arrows). Spaces between adjacent keratinocytes $(*)$ were readily apparent, but desmosome formation was sparse $(5,000 \times)$. are localized to the most highly differentiated keratinocytes of the subcorneal layer, we hypothesized that adherence would be promoted by terminal differentiation of keratinocytes. The principal factors that impact keratinocyte differentiation in our keratinocyte culture system are degree of keratinocyte confluence and concentration of calcium in the growth media (22-
29). Confluence was controlled by seeding keratinocytes at a constant density when initiating cultures, and by adjusting the calcium concentration when cells had reached $80 \%$ of confluence. Cultures were confluent by the time adherence assays were performed $7 \mathrm{~d}$ after adjusting the calcium concentration. State of terminal keratinocyte differentiation was determined
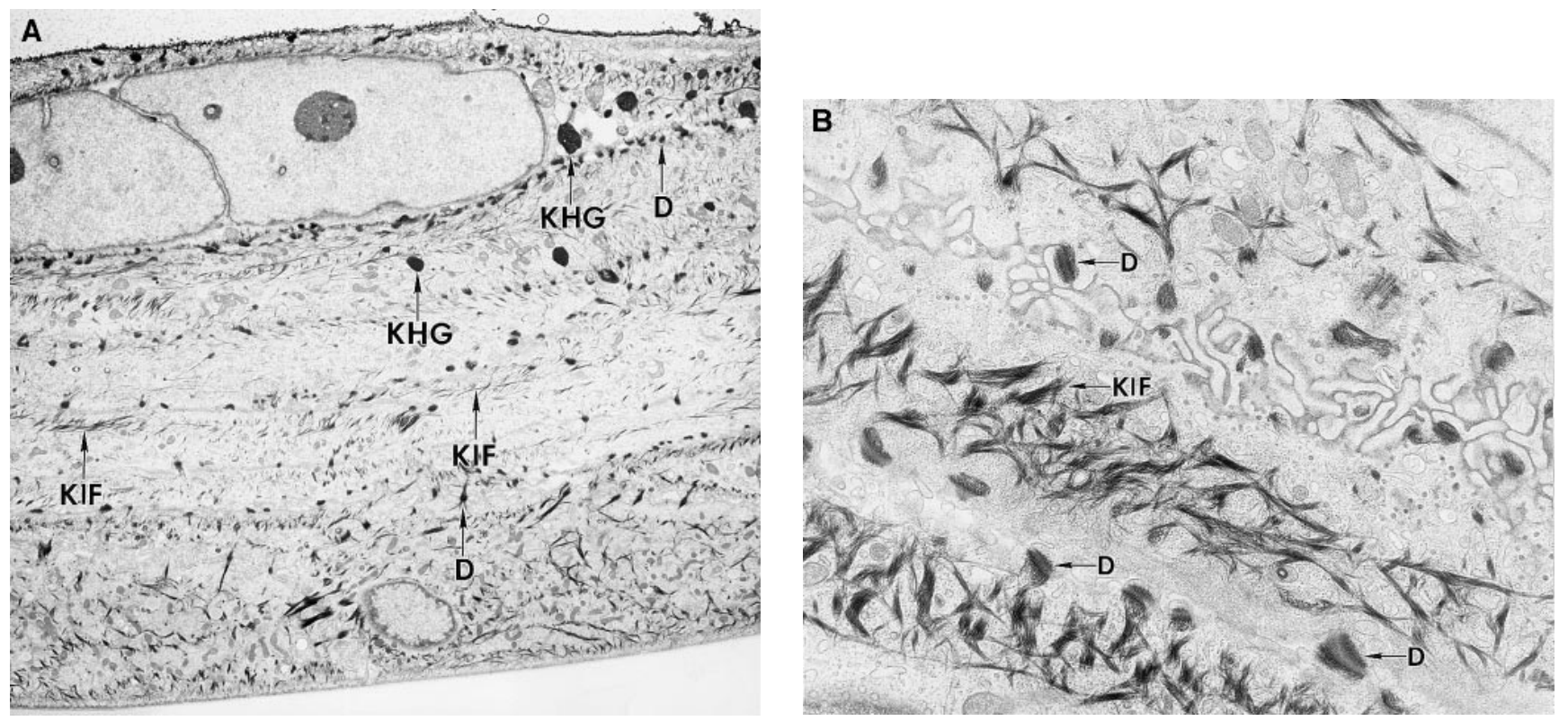

Figure 6. Electron micrographs of differentiated keratinocytes grown to confluence in medium containing $1.0 \mathrm{mM}$ calcium. $(A) \mathrm{Keratinocytes}$ were stratified to at least three cell layers, keratin intermediate filaments $(K I F)$ were dispersed throughout the cytoplasm, and keratohyalin granules $(K H G)$ were abundant $(2,000 \times)$. $(B)$ Numerous desmosomes $(D)$ were present between adjacent cells $(10,000 \times)$. 
morphologically by electron microscopy. Cells in $0.15 \mathrm{mM}$ calcium grew as a monolayer (Fig. 5); overlap on the apical surface occurred at occasional sites. Spaces between adjacent cells were relatively large, keratin intermediate filaments were located in a perinuclear distribution, and few desmosomes were present (Fig. 5). Desmosomes that formed were structurally normal, and keratohyaline granules were present. In contrast, keratinocytes differentiated in $1.0 \mathrm{mM}$ calcium were stratified to 3-6 cell layers (Fig. 6 A). Keratin intermediate filaments were dispersed throughout the cytoplasm, and extended to the plasma membrane where numerous desmosomal connections joined closely adherent, adjacent cells (Fig. $6 B$ ).

The gross difference in morphology between keratinocytes differentiated in $1.0 \mathrm{mM}$ calcium, and those that remained undifferentiated in $0.15 \mathrm{mM}$ calcium, particularly in the interaction of adjacent keratinocytes with one another, suggests that these two keratinocyte populations differed markedly in their expression of cell-surface proteins, presumably including cell adhesion molecules (33). We hypothesized that this difference would be reflected in the ability of $S$. pyogenes to adhere.

Keratinocytes that had been differentiated in $1.0 \mathrm{mM}$ calcium, or maintained in an undifferentiated state in $0.15 \mathrm{mM}$ calcium, were compared in adherence assays. The presence of calcium has been shown to affect adherence of some bacterial species (e.g., Yersinia pseudotuberculosis) to mammalian host cell receptors (34). Consequently, calcium was not included in the incubation media immediately before adherence assays to eliminate its presence as a confounding factor in assessment of the effect of keratinocyte differentiation on adherence. Adherence was three and fourfold greater to differentiated keratinocytes grown in $1.0 \mathrm{mM}$ and $1.5 \mathrm{mM}$ calcium, respectively,

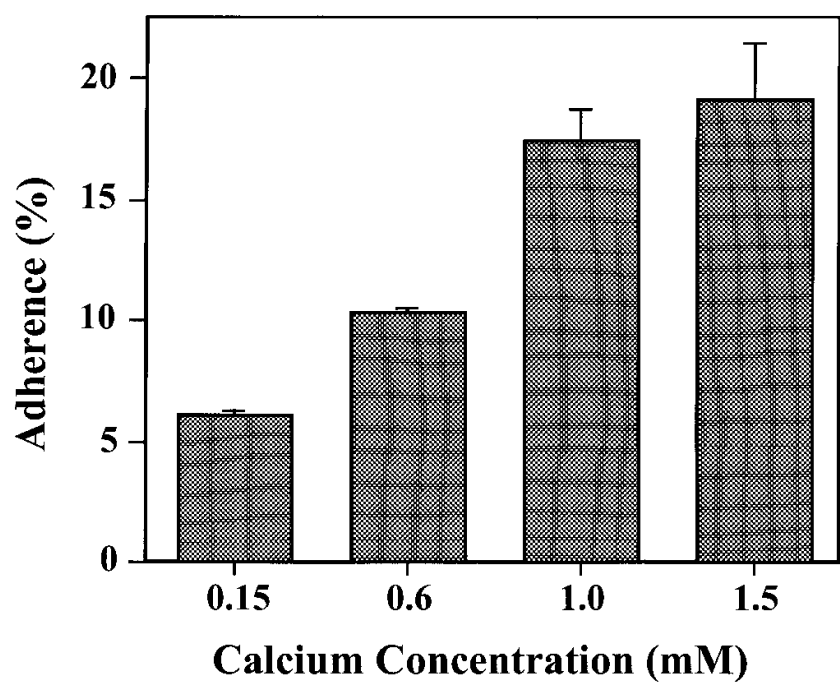

Figure 7. Adherence of Streptococcus pyogenes (strain 3732) to keratinocytes increased with keratinocyte terminal differentiation. Cultured keratinocytes were grown to $80 \%$ of confluence in keratinocyte growth medium containing $0.15 \mathrm{mM}$ extracellular calcium. The calcium concentration was either maintained at $0.15 \mathrm{mM}$ or increased to $0.6-1.5 \mathrm{mM}$ for an additional $7 \mathrm{~d}$ before initiating adherence by adding $1.4 \times 10^{8} \mathrm{CFU}$ of radiolabeled $S$. pyogenes per well at $4^{\circ} \mathrm{C}$. Adherence is expressed as the percent of the total cpm of bacteria added to each well that remained after washing and vortexing away nonadherent bacteria. Error bars represent \pm SD.

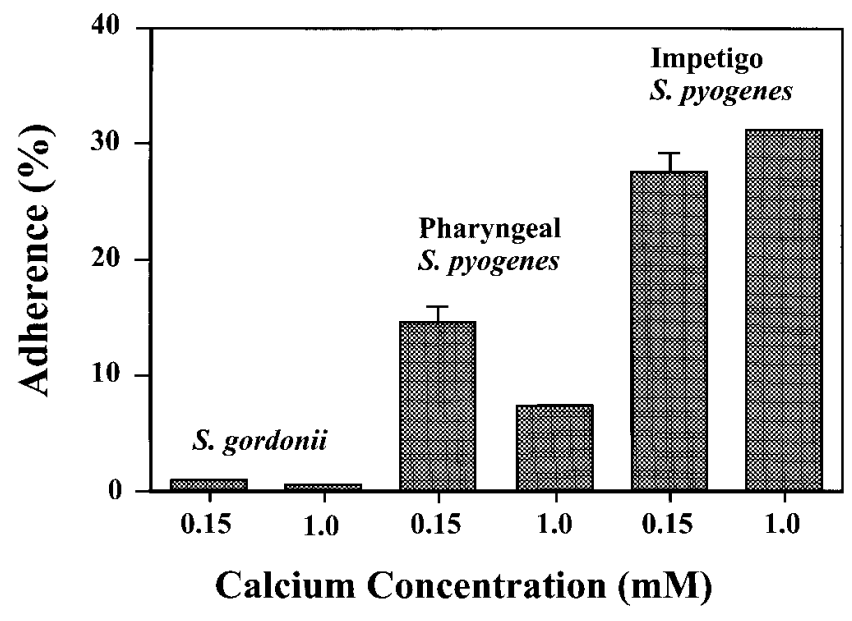

Figure 8. Keratinocyte adherence of Streptococcus pyogenes impetigo strain 3732 exceeded that of $S$. pyogenes pharyngeal strain 87263 and Streptococcus gordonii (Challis). Cultured keratinocytes were grown to $80 \%$ of confluence in keratinocyte growth medium containing $0.15 \mathrm{mM}$ extracellular calcium. The calcium concentration was either maintained at $0.15 \mathrm{mM}$ or increased to $1.0 \mathrm{mM}$ for an additional $5 \mathrm{~d}$ before initiating adherence at $4^{\circ} \mathrm{C}$ by adding $3.5 \times 10^{7}$, $6.7 \times 10^{7}$, or $1.8 \times 10^{8} \mathrm{CFU} /$ well of radiolabeled $S$. pyogenes impetigo strain 3732 , S. pyogenes pharyngeal strain $87-263$, or S. gordonii (Challis), respectively. Adherence is expressed as the percent of the total cpm of bacteria added to each well that remained after washing and vortexing away nonadherent bacteria. Error bars represent \pm SD.

compared with undifferentiated keratinocytes grown in 0.15 $\mathrm{mM}$ calcium (Fig. 7). Similarly, adherence to keratinocytes grown in $0.05 \mathrm{mM}$ or $0.09 \mathrm{mM}$ calcium to produce more undifferentiated cells was reduced to $65 \%$ and $61 \%$, respectively, compared with adherence to keratinocytes in $0.15 \mathrm{mM}$ calcium (data not shown). Greater adherence to differentiated keratinocytes was not due to exposure of a larger cell surface area for adherence. On the contrary, the surface area exposed on differentiated keratinocytes was less than that of undifferentiated keratinocytes because the latter had relatively large intercellular spaces to which the bacteria had access (Fig. 5).

In contrast to impetigo strain 3732, the nonpathogenic streptococcus, $S$. gordonii, adhered poorly to both differentiated and undifferentiated keratinocytes; $<1 \%$ of the inocula adhered to either keratinocyte population (Fig. 8). Furthermore, a serotype M1 strain of $S$. pyogenes (87-263) isolated from the throat of a patient with uncomplicated pharyngitis (20) bound less than strain 3732 to either keratinocyte population, and in contrast, showed greater (twofold) adherence to undifferentiated than differentiated keratinocytes (Fig. 8). This result is in agreement with Okada et al. (34), who reported that adherence of an M6 strain of $S$. pyogenes isolated from a patient with tonsillopharyngitis (35) was approximately two to threefold greater to undifferentiated ( $0.15 \mathrm{mM}$ calcium) than differentiated (1.2 $\mathrm{mM}$ calcium) keratinocytes. In multiple experiments, keratinocyte differentiation consistently promoted the adherence of strain 3732 and decreased the adherence of strain 87-263, although the magnitude of the effects varied depending on the person from whom the keratinocytes were isolated.

Adherence of S. pyogenes to either differentiated or undif- 

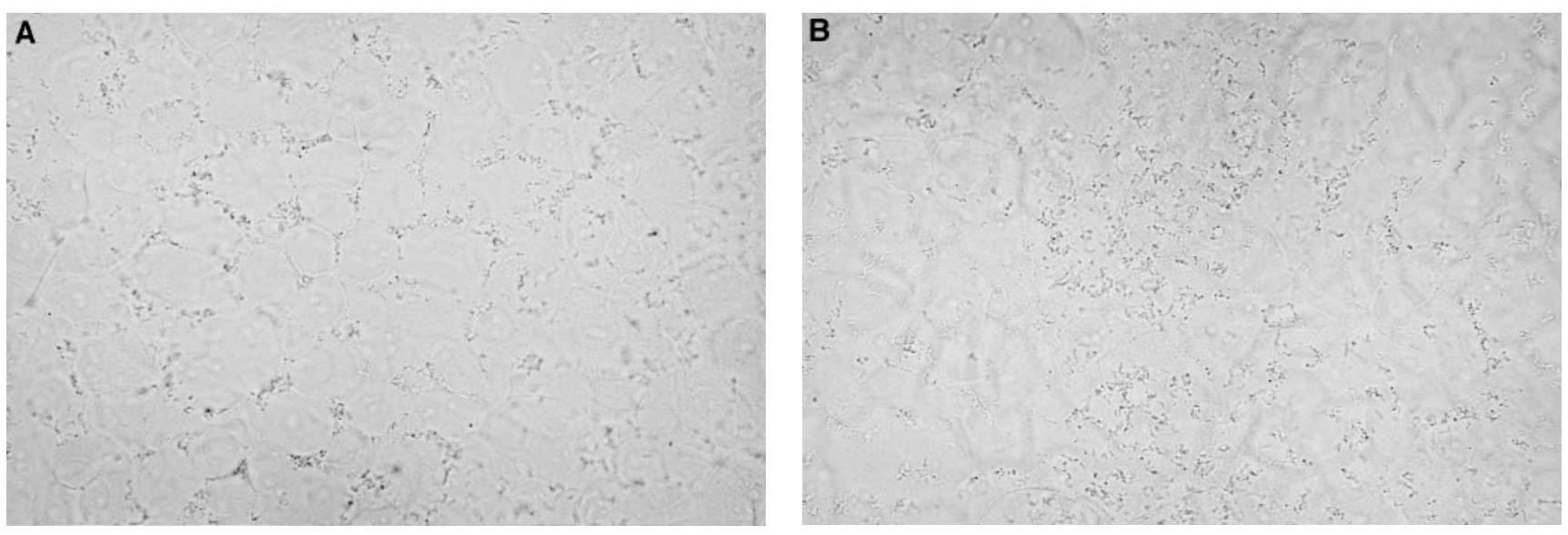

Figure 9. Streptococcus pyogenes (strain 3732) adhered to cultured human keratinocytes preferentially at sites of cell-cell contact. Keratinocytes were grown to $80 \%$ of confluence in keratinocyte growth medium containing $0.15 \mathrm{mM}$ extracellular calcium. The calcium concentration was either $(A)$ maintained at $0.15 \mathrm{mM}$ or $(B)$ increased to $1.0 \mathrm{mM}$ for an additional $7 \mathrm{~d}$ before adding $S$. pyogenes. Light microscopy was performed after incubation of bacteria with keratinocytes for $24 \mathrm{~h}$ at $4^{\circ} \mathrm{C}(40 \times)$.

ferentiated keratinocytes was found to occur preferentially to sites of contact between keratinocytes (Figs. 4 and 9). Distribution of the bacteria attached to differentiated keratinocytes appeared to be more random, however, with an increased proportion of adherent bacteria scattered over the apical surface (Fig. 9 B). We postulated that adherence of $S$. pyogenes at sites of cell-cell contact might be reflective of binding to cellular adhesion molecules (e.g., cadherins, integrins), and that adherence might be subject to modulation by calcium as shown for $Y$. pseudotuberculosis (36).

To assess the importance of calcium in modulating adherence of $S$. pyogenes to keratinocytes, adherence to differentiated and undifferentiated keratinocytes was examined with and without calcium present in the media during blockade of nonspecific sites for adherence $(2 \mathrm{~h})$ and during the adherence assay $(4 \mathrm{~h})$. Adherence to either differentiated or undifferentiated keratinocytes was enhanced 1.7 -fold by the presence of calcium (Fig. 10), suggesting that calcium modulated the interaction between bacteria and keratinocytes. Again, greater adherence to differentiated than undifferentiated keratinocytes, independent of the presence of calcium, suggests that keratinocyte differentiation promoted the adherence of $S$. pyogenes (Fig. 10).

\section{Discussion}

We hypothesized that skin infection with $S$. pyogenes occurs when the corneal layer is disrupted and bacteria gain access to epidermal keratinocytes. There, they adhere preferentially to receptors present predominantly on terminally differentiated keratinocytes. In this paper, we report the first in vitro investigation that demonstrates the adherence of $S$. pyogenes to skin cells in a manner that emulates human impetigo, whereby bacteria adhere preferentially to more highly differentiated keratinocytes.

Our adherence assay, using an M52 impetigo isolate of $S$. pyogenes, quantified the number of bacteria bound specifically to keratinocytes. Adherence occurred in a time- and inoculumdependent manner, suggestive of a specific receptor-mediated process. Preferential adherence to more highly differentiated keratinocytes was specific to the pathogenic impetigo strain of $S$. pyogenes. The relative inability of $S$. gordonii to adhere to keratinocytes may explain, at least in part, its lack of pathogenicity in the skin, and further supports the hypothesis that adherence is an important initiating step in the pathogenesis of cutaneous infections. Decreased adherence of the pharyngeal strain of $S$. pyogenes to differentiated compared with undifferentiated keratinocytes further highlights the specific nature of

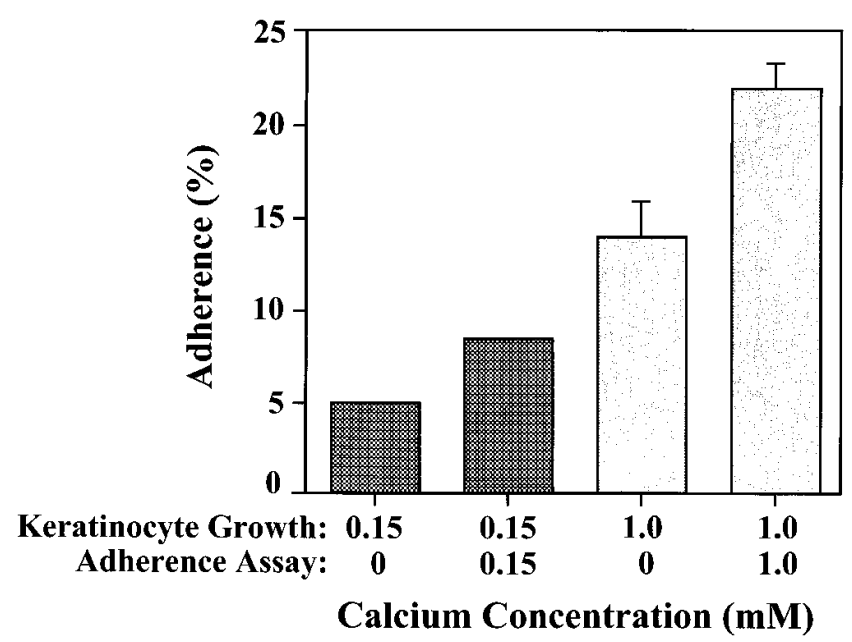

Figure 10. Adherence of Streptococcus pyogenes (strain 3732) to keratinocytes was increased in the presence of calcium. Cultured keratinocytes were grown to $80 \%$ of confluence in keratinocyte growth medium containing $0.15 \mathrm{mM}$ extracellular calcium. The calcium concentration was either maintained at $0.15 \mathrm{mM}$ (hatched bars) or increased to $1.0 \mathrm{mM}$ (shaded bars) for an additional $7 \mathrm{~d}$ before measuring adherence of $S$. pyogenes. Calcium was either excluded from incubation media or was included during blockade of nonspecific adherence as well as during the adherence assay. Adherence was initiated by adding $2.0 \times 10^{8} \mathrm{CFU}$ of radiolabeled $S$. pyogenes per well at $4^{\circ} \mathrm{C}$. Error bars represent \pm SD. 
the enhanced interaction of skin-trophic $S$. pyogenes with receptors on differentiated keratinocytes. Okada et al. (34) also found that binding of a pharyngeal M6 strain of $S$. pyogenes to differentiated keratinocytes in $1.2 \mathrm{mM}$ calcium was two to threefold lower compared with undifferentiated keratinocytes in $0.15 \mathrm{mM}$ calcium. They used semiquantitative methods, basing their conclusions on visualization of adherent bacteria by light microscopy, and did not demonstrate the state of differentiation of their keratinocytes. Nevertheless, our quantitative assay corroborates their finding, and demonstrates that there is a difference in the nature of the interaction of impetigo compared with pharyngeal strains of $S$. pyogenes with keratinocytes. Enhanced adherence of the impetigo strain 3732 (but not pharyngeal strains of $S$. pyogenes or a nonpathogenic streptococcus) to more highly differentiated keratinocytes emulates impetigo, and provides a model system for investigating the pathogenesis of cutaneous infections, particularly the molecular mechanisms of interaction of skin-trophic $S$. pyogenes with keratinocytes.

It has long been known that strains of $S$. pyogenes isolated from skin infections differ from pharyngeal isolates in their M-protein serotype and expression of opacity factor (18). More recently, differences in their genomes have been described, including distinct patterns of chromosomal arrangements of the emm genes that encode the M- and M-like proteins (19). Furthermore, unlike most pharyngeal isolates, impetigo strains typically are able to bind $\mathrm{IgG}$ and $\operatorname{IgA}$ due to the expression of additional genetic elements ( $f c r$ and enn genes, respectively) within the virR regulon, the largest cluster of linked and coordinately regulated genes described to date in S. pyogenes (3739). Consequently, it is not surprising that adherence of an impetigo isolate of $S$. pyogenes to keratinocytes would differ from that of a respiratory isolate, and that the pattern of adherence, with increased adherence to more highly differentiated keratinocytes, would more closely model the histopathology of superficial streptococcal skin infections in humans.

In studies of cutaneous binding of a genetically engineered M6 pharyngeal strain of $S$. pyogenes, the C-repeat domain of $\mathrm{M}$ protein mediated adherence to the CD46 molecule on keratinocytes, while protein $\mathrm{F}$ was responsible for binding to Langerhans cells of the skin $(40,41)$. The relevance of these molecular interactions to the pathogenesis of skin infections is not clear, and must be confirmed with a skin-trophic, impetigo isolate of $S$. pyogenes.

We observed by electron microscopy that $S$. pyogenes adhered by the tips of pilus-like projections from the cell wall, supporting the hypothesis that attachment involves a specific bacteria-host cell interaction. Given that calcium-stimulated keratinocyte terminal differentiation promoted adherence, we postulate that expression of host-cell receptors for adherence of strains of $S$. pyogenes that are pathogenic for the skin may increase with terminal differentiation.

A plethora of metabolic and biochemical changes accompany terminal differentiation of keratinocytes, including formation of desmosomes (25), synthesis and posttranslational processing of cornified envelope proteins and keratin intermediate filament aggregating protein $(27,28)$, production of lipids and their packaging in lamellar bodies for export to the intercellular space where they are integral to epithelial barrier function (42), and alterations in synthesis and distribution of cellular adhesion molecules (43). The changes appear to be reflected in the marked difference in cell-to-cell association observed by electron microscopy between keratinocytes in our two populations. Undifferentiated keratinocytes (in $0.15 \mathrm{mM}$ calcium) grew as a monolayer, had gaps on the lateral surface between adjacent keratinocytes, and formed few desmosomes, while differentiated keratinocytes (in $1.0 \mathrm{mM}$ calcium) became stratified and were closely adherent with numerous desmosomal connections. Based on the localization of adherent bacteria primarily to sites of contact between adjacent keratinocytes, it seems plausible that the host-cell receptor for adherence may be a molecule that mediates adhesion between keratinocytes. The bacterial pathogens identified thus far that interact with mammalian cellular adhesion molecules (e.g., integrins), however, typically have been intracellular parasites that, subsequent to attachment, are internalized through rearrangement of underlying host cytoskeletal elements attached to the cellular adhesion molecules (e.g., actin microfilaments; $42,44)$. Internalization appears to be an important step in intercellular spread of these pathogens. It is not known whether internalization of $S$. pyogenes plays a role in the pathogenesis of skin infections (45).

In addition to promoting adherence through stimulation of keratinocyte differentiation, calcium further modulated the adherence process when it was present in the incubation media during adherence assays. Calcium may have mediated this effect through several potential mechanisms, including the following: (a) an increase in number of a single type of receptor; (b) induction of additional type(s) of host cell receptor(s); (c) facilitation of a more avid association between bacterial adhesin and host cell receptor; $(d)$ increased exposure of receptors through changes in their conformation; or $(e)$ a change in the number, exposure, and/or function of bacterial adhesins. The nature of the host cell receptor and bacterial adhesin, and the role of calcium in the adherence process, are the subject of ongoing investigations in our laboratory. Modulation of adherence by calcium has been described for $Y$. pseudotuberculosis (36). This effect occurs because of the presence of calciumbinding domains on $\beta 1$-integrin cellular adhesion molecules, the mammalian host cell receptor for the bacterial adhesin (36, 46). Enhancement of adherence by calcium also has been reported for Candida albicans (47), which binds to host cells by an integrin-like adhesin (48).

Use of differentiated, cultured human keratinocytes in an experimental model that emulates human impetigo may provide insight into the bacterial adhesin(s) and keratinocyte receptor(s) involved in adherence, and the role of adherence in pathogenesis of cutaneous streptococcal infections. Through understanding of the molecular pathogenesis of these infections, it may be possible to devise new rational approaches to their prevention and management.

\section{Acknowledgments}

We acknowledge the technical assistance of Diane Zebert in measuring ionized calcium levels, and Laurel McElvoy in culturing keratinocytes.

This research was supported by Training Grant HD 07233 from the National Institutes of Health (G.L. Darmstadt), the William Weston Research Grant from the Society for Pediatric Dermatology (G.L. Darmstadt), the Dermatology Endowed Research Fund (P. Fleckman), Public Health Service grant AR-21557 (P. Fleckman), and grant AI30068 from the National Institutes of Health (C.E. Rubens). 


\section{References}

1. Darmstadt, G.L., and S.M. Marcy. 1996. Skin infections. In Principles and Practice of Pediatric Infectious Disease. L. Pickering, C. Prober, and S. Long, editors. Churchill-Livingstone, New York. 476-517.

2. Darmstadt, G.L. 1997. Staphylococcal and streptococcal skin infections. In Diagnosis and Treatment of Skin Infections. M. Harahap, editor. Blackwell Science Ltd., Oxford. 7-115.

3. Darmstadt, G.L. 1997. Oral antibiotics for treatment of uncomplicated skin infections in children. Pediatr. Infect. Dis. J. 16:227-240.

4. Stevens, D.L., M.H. Tanner, J. Winship, R. Swarts, K.M. Ries, P.M. Schlievert, and E. Kaplan. 1989. Severe group A streptococcal infections associated with toxic shock-like syndrome and scarlet fever toxin A. N. Engl. J. Med. 321:1-7.

5. Stevens, D.L. 1992. Invasive group A streptococcal infections. Clin. Infect. Dis. 14:2-13.

6. Cleary, P.P., E.L. Kaplan, J.P. Handley, A. Wlazlo, M.H. Kim, A.R. Hauser, and P.M. Schlievert. 1992. Clonal basis for resurgence of serious Streptococcus pyogenes disease in the 1980s. Lancet. 339:518-521.

7. Wolf, J.E., and L.G. Rabinowitz. 1995. Streptococcal toxic shock-like syndrome. Arch. Dermatol. 131:73-77.

8. Tunnessen, W.W., Jr. 1984. A survey of skin disorders seen in pediatric general and dermatology clinics. Pediatr. Dermatol. 1:219-222.

9. Hayden, G.F. 1985. Skin diseases encountered in a pediatric clinic. Am. J. Dis. Child. 139:36-38.

10. Darmstadt, G.L., and A.T. Lane. 1994. Impetigo: an overview. Pediatr. Dermatol. 4:293-303.

11. Lookingbill, D.P. 1985. Impetigo. Pediatr. Rev. 7:177-181.

12. Kupper, T.S. 1990. Immune and inflammatory processes in cutaneous tissues. J. Clin. Invest. 86:1783-1789.

13. Barker, J.N.W.N., R.S. Mitra, C.E.M. Griffiths, V.M. Dixit, and B.J. Nickoloff. 1991. Keratinocytes as initiators of inflammation. Lancet. 337:211214.

14. Hasty, D.L., I. Ofek, H.S. Courtney, and R.J. Doyle. 1992. Multiple adhesins of streptococci. Infect. Immun. 60:2147-2152.

15. Sela, S., A. Aviv, I. Burstein, M.G. Caparon, and E. Hanski. 1993. Protein F: an adhesin of Streptococcus pyogenes binds fibronectin via two distinct domains. Mol. Microbiol. 10:1049-1055.

16. Clark, R.A.F. 1990. Fibronectin matrix deposition and fibronectin receptor expression in healing and normal skin. J. Investig. Dermatol. 94:128S$134 \mathrm{~S}$.

17. Leyden, J.J., R. Stewart, and A.M. Kligman. 1980. Experimental infections with group A streptococci in humans. J. Investig. Dermatol. 75:196-201.

18. Wannamaker, L.W. 1970. Differences between streptococcal infections of the skin and pharynx. N. Engl. J. Med. 282:78-85.

19. Bessen, D., and V. Fischetti. 1990. A human IgG receptor of group A streptococci is associated with tissue site infection and streptococcal class. J. Infect. Dis. 161:747-754.

20. LaPenta, D., C. Rubens, E. Chi, and P.P. Cleary. 1994. Group A streptococci efficiently invade human respiratory epithelial cells. Proc. Natl. Acad. Sci. USA. 91:12115-12119.

21. Piepkorn, M., P. Hovingh, A. Dillberger, and A. Linker. 1995. Divergent population of proteoglycan and glycosaminoglycan free chain expression in human keratinocytes and melanocytes. In Vitro Cell. Dev. Biol. Anim. 31: $536-541$

22. Hennings, H., D. Michael, C. Cheng, P. Steinert, K. Holbrook, and S.H. Yuspa. 1980. Calcium regulation of growth and differentiation of mouse epidermal cells in culture. Cell. 19:245-254.

23. Hennings, H., and K.A. Holbrook. 1983. Calcium regulation of cell-cell contact and differentiation of epidermal cells in culture. Exp. Cell. Res. 143: $127-142$.

24. Fuchs, E. 1990. Epidermal differentiation: the bare essentials. J. Cell Biol. 111:2807-2814.

25. Watt, F.M., D.L. Mattey, and D.R. Garrod. 1984. Calcium-induced reorganization of desmosomal components in cultured human keratinocytes. J. Cell
Biol. 99:2211-2215.

26. Li, L., T. Tennenbaum, and S.H. Yuspa. 1996. Suspension-induced murine keratinocyte differentiation is mediated by calcium. J. Investig. Dermatol. 106:254-260.

27. Yuspa, S.H., A.E. Kilkenny, P.M. Steinert, and D.R. Roop. 1989. Expression of murine epidermal differentiation is tightly regulated by restricted extracellular calcium concentrations in vitro. J. Cell Biol. 109:1207-1217.

28. Hohl, D., U. Lichti, D. Breitkreutz, P.M. Steinert, and D.R. Roop. 1991. Transcription of the human loricrin gene in vitro is induced by calcium and cell density and suppressed by retinoic acid. J. Investig. Dermatol. 96:414-418.

29. Poumay, Y., and M.R. Pittelkow. 1995. Cell density and culture factors regulate keratinocyte commitment to differentiation and expression of suprabasal K1/K10 keratins. J. Investig. Dermatol. 104:271-276.

30. Ladenson, J.H., and G.N. Bowers, Jr. 1973. Free calcium in serum. 1. Determination with the ion-specific electrode, and factors affecting the results. Clin. Chem. 19:565-574.

31. Chi, E., T. Mehl, D. Nunn, and S. Lory. 1991. Interaction of Pseudomonas aeruginosa with A549 pneumocyte cells. Infect. Immun. 59:822-828.

32. Rubens, C.E., S. Smith, M. Hulse, E.Y. Chi, and G. van Belle. 1992. Respiratory epithelial cell invasion by group B streptococci. Infect. Immun. 60 : 5157-5163.

33. Wilson, C.B., R.F. Jacobs, and A.L. Smith. 1982. Cellular antibiotic pharmacology. Semin. Perinatol. 6:205-213.

34. Okada, N., A.P. Pentland, P. Falk, and M.G. Caparon. 1994. M protein and protein $\mathrm{F}$ act as important determinants of cell-specific tropism of Streptococcus pyogenes in skin tissue. J. Clin. Invest. 94:965-977.

35. Scott, J.R., P.C. Guenthner, L.M. Malone, and V.F. Fischetti. 1986. Conversion of an $\mathrm{M}-$ group A streptococcus to $\mathrm{M}+$ by transfer of a plasmid containing an M6 gene. J. Exp. Med.164:1641-1651.

36. Isberg, R.R., and J.M. Leong. 1990. Multiple $b_{1}$ chain integrins are receptors for invasin, a protein that promotes bacterial penetration into mammalian cells. Cell. 60:861-871.

37. Podbielski, A., A. Flosdorff, and J. Weber-Heynemann. 1995. The group A streptococcal virR49 gene controls expression of four structural vir regulon genes. Infect. Immun. 63:9-20.

38. Podbielski, A. 1993. Three different types of organization of the vir regulon in group A streptococci. Mol. Gen. Genet. 237:287-300.

39. Haanes, E.J., D.G. Heath, and P.P. Cleary. 1992. Architecture of the vir regulons of group A streptoccocci parallels opacity factor phenotype and $\mathrm{M}$ protein class. J. Bacteriol. 174:4967-4976.

40. Perez-Casal, J., N. Okada, M.G. Caparon, and J.R. Scott. 1995. Role of the conserved C-repeat region of the M protein of Streptococcus pyogenes. Mol. Microbiol. 15:907-916.

41. Okada, N., M.K. Liszewski, J.P. Atkinson, and M. Caparon. 1995. Membrane cofactor protein (CD46) is a keratinocyte receptor for the M protein of the group A streptococcus. Proc. Natl. Acad. Sci. USA. 92:2489-2493.

42. Elias, P.M., and K.R. Feingold. 1992. Lipids and the epidermal water barrier: metabolism, regulation, and pathophysiology. Semin. Dermatol. 11: 176-182.

43. Symington, B.E., and W.G. Carter. 1995. Modulation of epidermal differentiation by epiligrin and integrin $\mathrm{a}_{3} \mathrm{~b}_{1}$. J. Cell Sci. 108:831-838.

44. Finlay, B.B. 1990. Cell adhesion and invasion mechanisms in microbial pathogenesis. Curr. Opin. Cell Biol. 2:815-820.

45. Schrager, H.M., J.G. Rheinwald, and M.R. Wessels. 1996. Hyaluronic acid capsule and the role of streptococcal entry into keratinocytes in invasive skin infections. J. Clin. Invest. 98:1954-1958.

46. Gailit, J.O., and R.A.F. Clark. 1993. Integrins. Adv. Dermatol. 8:129 153.

47. Klotz, S.A., M.J. Rutten, R.L. Smith, S.R. Babcock, and M.D. Cunningham. 1993. Adherence of Candida albicans to immobilized extracellular matrix proteins is mediated by calcium-dependent surface glycoproteins. Microb. Pathog. 14:133-147.

48. Gale, C., D. Finkel, N. Tao, M. Meinke, M. McClellan, J. Olson, K. Kendrick, and M. Hostetter. 1996. Cloning and expression of a gene encoding an integrin-like protein in Candida albicans. Proc. Natl. Acad. Sci. 93:357-361. 